\title{
SER IDOSO E O PROCESSO DO ENVELHECIMENTO: SAÚDE PERCEBIDA
}

\author{
Being an elderly and the process aging: perceived health \\ Ser anciano y el proceso de envej ecimiento: salud percibida
}

Juliana Araújo Dias ${ }^{1}$

Cristina Arreguy-Sena ${ }^{2}$

Paulo Ferreira Pinto ${ }^{3}$

Luciene Carnevale de Souza ${ }^{4}$

\section{RESUMO}

Pesquisa qualitativa tipo survey realizada em Rio Novo-Minas Gerais que objetivou analisar a concepção dos idosos sobre envelhecimento e suas percepções de serem/estarem idosos. Amostra por tipicidade composta por 20 voluntários com 60 ou mais anos, cadastrados no Programa de Vacinação do Município. Excluíram-se pessoas com: alteração de consciência; dissociações moderadas do pensamento; dificuldade para verbalização; e moradores rurais. Identificaram-se 385 crenças, segundo Rokeach, que tenderam em $76,3 \%$ à centralidade. Duas concepções de envelhecimento foram identificadas (nova oportunidade na vida e deterioração corporal, da autonomia e das relações). A própria idade e o nível de inserção social foram os critérios para conceituar quem não se sente idoso ou envelhecido e quem é ou não envelhecido, respectivamente.

Palavras-chave: Enfermagem. Idoso. Envelhecimento. Cultura.

\begin{abstract}
Qualitative research type survey conducted in Rio Novo, Minas Gerais, which aimed to analyze the design of the elderly about aging and their perception of being /are elderly. Sample by typicality comprised in 20 volunteers with the age of 60 or more years, registered in the Immunization Program of the City. We excluded people with: altered consciousness; moderate dissociation of thought; difficulty verbalizing, and rural residents. 385 beliefs were identified, according to Rokeach, who tended to the centrality in $76.3 \%$. Predominant conceptions of aging were identified (new chance at life and bodily decay, autonomy and relations). The age itself and the level of social integration were the criteria for conceptualizing those who do not feel old or older and who is aged or not respectively.
\end{abstract}

Keywords: Nursing. Aged. Aging. Culture.

\section{Resumen}

La investigación cualitativa de tipo encuesta realizada en Rio Novo, Minas Gerais, que tuvo como objetivo analizar el diseño de los ancianos acerca del envejecimiento y su percepción de ser/estar con edad avanzada. Muestra por tipicidad compuesta de 20 voluntarios con 60 o más años, registrados en el Programa de Inmunizaciones de la Ciudad. Se excluyeron las personas con: la conciencia alterada; disociación moderada de pensamiento; dificultad para verbalizar; los residentes rurales. Según Rokeach, fueron identificadas 385 creencias que tendieron en $76,3 \%$ a la centralidad. Dos concepciones del envejecimiento fueron predominantes (nueva oportunidad en la vida y la decadencia física, la autonomía y las relaciones). La edad y el nivel de integración social fueron los criterios usados para la conceptualización de los que no se sienten ancianos o envejecidos y que es de edad avanzada o no, respectivamente.

Palabras clave: Enfermería. Anciano. Envejecimiento. Cultura.

${ }^{1}$ Enfermeira da Unidade de Pronto Atendimento de São Pedro, Universidade Federal de Juiz de Fora-MG. Brasil. E-mail: ju_araujod@hotmail.com,²Enfermeira, Doutora e Professora Associada da Faculdade de Enfermagem da UFJF. Juiz de Fora - MG. Brasil. E-mail: cristina.arreguy@ufj.edu.br, ${ }^{3}$ Professor de Educação Física, Doutorando pela Universidade Nova de Lisboa, Portugal e Professor Adjunto da UFJF. Juiz de Fora - MG. Brasil. E-mail: paulo.ferpinto@terra.com.br, ${ }^{4}$ Acadêmica de Enfermagem da Faculdade de Enfermagem da UFJF e bolsista da FAPEMIG. Juiz de Fora - MG. Brasil. E-mail: lucienecarnevale@hotmail.com 


\section{INTRODUÇ̃̃O}

Embora 65 anos de idade ou mais seja o critério usado para identificar uma pessoa idosa nos países desenvolvidos, ${ }^{1}$ no Brasil, a referência é a partir dos 60 anos, sendo a concepção de envelhecimento ativo retratada pela: manutenção da capacidade funcional; assistência às necessidades de saúde do idoso; reabilitação da capacidade funcional comprometida; capacitação de recursos humanos especializados; apoio ao desenvolvimento de cuidados informais e de pesquisas e pela promoção do envelhecimento saudável. ${ }^{1}$ Isso equivale a aumentar a expectativa de vida saudável e a qualidade de vida para as pessoas, mantendo-as participantes nas questões sociais, econômicas, culturais, espirituais e civis. ${ }^{2}$

0 fato de o modelo demográfico brasileiro apresentar um aumento absoluto e relativo da população com 60 anos de idade ou mais, aliado à melhoria das condições e expectativas de vida da população como uma resposta às demandas sociais, ${ }^{3-5}$ repercutiu sobre o perfil da pirâmide populacional. ${ }^{6}$

Investigar a percepção das pessoas com mais de 60 anos de idade sobre seu processo de envelhecimento constitui uma contribuição capaz de redimensionar o impacto do fenômeno de agrizalhamento. Diante do exposto, esse estudo visa analisar a concepção dos idosos a respeito do envelhecimento e sua percepção de ser/estar ou não idoso, identificar se elas se consideram idosas ou envelhecidas e qual o conceito que possuem sobre ser envelhecido ou idoso.

A presente investigação justifica-se pelo fato de o processo de envelhecimento brasileiro ser uma realidade próxima de repercussão marcante sobre as políticas sociais e econômicas do país que requerem do Enfermeiro e dos profissionais da área de saúde uma compreensão de vida sensível aliada a competência técnica, comunicacional e política capaz de auxiliar a sociedade a resgatar as relações interpessoais e familiares.

\section{REVISÃO LITERÁRIA}

A cultura é fator preponderante para a compreensão do "processo de envelhecimento ativo", uma vez que influencia no estilo de vida adotado ao longo do ciclo da vida a ponto de interferir sobre a qualidade do processo de envelhecimento.?

Além dos valores culturais, as tradições determinam como uma sociedade encara as pessoas idosas e o processo de envelhecimento. ${ }^{2}$ Cabe destacar que há influência das crenças sobre a "saúde percebida", uma vez que a saúde percebida se estrutura a partir da auto-observação e julgamento de uma pessoa, quando analisa comparativamente sua própria condição com a do outro, sendo inegável a influência de parâmetros pessoais e sociais neste julgamento. ${ }^{8-9}$

A "saúde percebida" é concebida como a avaliação subjetiva que cada pessoa faz a respeito da qualidade de sua saúde física e mental, podendo incluir uma avaliação atual ou pregressa comparativamente de sua capacidade funcional ou incluir julgamentos de valor sobre a expectativa que se tem sobre sua condição de saúde. ${ }^{8-9}$ Ela representa uma integração individual de muitos aspectos do conceito de saúde, tais como a capacidade de realizar determinadas tarefas, o statusfuncional e o status de saúde. ${ }^{10}$

As formas mais divulgadas para apreensão da "saúde percebida" são relatos de: doenças; consumo de medicamentos, de dor e de desconfortos; alterações percebidas na cognição e autoeficácia, quer seja no âmbito físico ou cognitivo. ${ }^{8}$ Cabe destacar que, mesmo entre pessoas com a mesma idade, existem variações significativas na percepção do estado de saúde, da participação e de autonomia. Tal fato reafirma como o "processo de envelhecimento" é vivenciado de forma peculiar, como ele não se restringe a uma faixa etária e como é consequência de um estilo e de uma concepção adotada ao longo do ciclo vital. ${ }^{11}$

Crença, na presente pesquisa, é compreendida como o suporte cognitivo-social e/ou emocional para convicção de uma pessoa diante de um fato, acontecimento real ou probabilístico, explicando a base em que se fundamenta uma pessoa para adotar uma atitude, comportamento ou pensamento. Segundo Rokeach um sistema de crenças possui cinco categorias, a saber: 1) primitivas de consenso unânime ou do tipo "A"; 2) primitivas de consenso zero ou do tipo "B"; 3 ) de autoridade ou do tipo "C"; 4) derivadas ou do tipo "D" e 5) inconsequentes ou do tipo "E". ${ }^{2}$ Uma pessoa pode possuir várias crenças sobre um mesmo fato, sendo estas estruturadas em cinco categorias que estão, imaginariamente, localizados em um eixo de maneira harmônico a ponto de conferir estabilidade ao sistema de crenças. É possível haver intercâmbio entre elas, possibilitando a análise do sistema de crenças quanto à sua posição no eixo imaginário (centralidade ou perifericidade). ${ }^{12}$ A localização da crença no eixo de centralidade/perifericidade possibilita inferir o quanto as crenças são fixas ou passíveis de serem modificadas e pode ser comparado a um átomo, no qual os prótons são as crenças centrais e os elétrons, as periféricas.

As crenças do tipo "A" "são as mais centrais dentro do sistema de crenças, apreendidas pelo encontro direto com 0 objeto de crença e reforçadas pelo consenso unânime entre pessoas e grupos. Elas representam as "verdades básicas" de uma pessoa sobre a realidade física, social e a natureza do eu". ${ }^{12}$ As crenças do tipo "B" também "são aprendidas pelo contato direto com o objeto de crença, porém têm como referência o próprio eu, envolvendo diretamente a existência e a autoidentidade. Não dependem do consenso de pessoas ou grupos para a sua manutenção". ${ }^{12}$ As crenças do tipo "C" dizem respeito à autoridade que é conferida ou atribuída às pessoas. "Elas surgem e são ampliadas a partir de experiências com grupos sociais". ${ }^{12}$ As crenças do tipo "D" constituem um tipo específico de crença de autoridade, na qual a autoridade é originada da influência dos meios de comunicação, de pessoas, de objetos ou de instituições. ${ }^{12}$ As crenças do tipo "E" consistem 
em situações de preferência, não tendo uma justificativa plausível para sua ocorrência. Elas "estão relacionadas às questões de gosto" e são "consideradas inconsequentes por ter pouca ou nenhuma implicação sobre outras crenças". ${ }^{12}$

Para uma melhor compreensão do sistema de crenças, é importante ressaltar os seguintes pressupostos: 1) atitude é formada pela organização de crenças inter-relacionadas;2) qualquer crença representa uma predisposição para responder de um modo preferencial ao objeto (foco de sua atenção) e pode possuir tanto um componente afetivo, cognitivo ou comportamental; 3) o afeto ou cognição positiva ou negativa podem ser dirigidos ao objeto daquela atitude ou a outros objetos envolvidos (ou situações paralelas). Exemplo são as motivações que fazem com que um comportamento de solidariedade ou desprezo seja manifestado a respeito de uma pessoa, embora haja concordância ou discordância deste comportamento do ponto de vista, do modo de viver ou de agir de outra pessoa ou grupo; 4) as possibilidades de resposta diante dos objetos, das "situações paralelas" ou comportamentos estão positivamente interligados, uma vez que são motivados pela mesma atitude; 5) um comportamento é o resultado da interação entre atitude (aspectos psicológicos- o que eu penso) e a definição da situação (aspectos objetivos-o que eu faço). ${ }^{12}$ Quando uma atitude possui conteúdo equivalente a uma situação, o comportamento é a função da interação entre duas atitudes e da relação com um objeto e com outra situação. ${ }^{12}$

0 fato de uma atitude ser formada pela organização de crenças inter-relacionadas, justifica por que ela descreve, avalia e defende uma ação que possui três componentes, ou seja, o componente cognitivo, afetivo e comportamental. Quando uma crença é ativada por algum fator (quer ele seja uma situação ou um objeto) ela desencadeia uma resposta (cognitiva, afetiva ou comportamental) em relação ao fator, ou seja, em relação ao objeto, à situação de atitude ou à manutenção desta atitude em si mesma. Partindo do pressuposto de que o objeto da atitude insere-se numa situação sobre a qual recai uma atitude, conclui-se que, para ocorrer o comportamento social é necessário ativar, pelo menos, duas atitudes que interajam entre si, sendo que uma delas deve referir-se ao objeto e a outra, à situação. Este fato permite que novas crenças sejam garimpadas a partir da reunião de atitudes.

\section{MÉTODOS E TÉCNICAS}

A cultura é fator preponderante para a compreensão do "processo de envelhecimento ativo", uma vez que influencia no estilo de vida adotado ao longo do ciclo da vida a ponto de interferir sobre a qualidade do processo de envelhecimento. ${ }^{7}$

Além dos valores culturais, as tradições determinam como uma sociedade encara as pessoas idosas e o processo de envelhecimento. ${ }^{2}$ Cabe destacar que há influência das crenças sobre a "saúde percebida", uma vez que a saúde percebida se estrutura a partir da auto-observação e julgamento de uma pessoa, quando analisa comparativamente sua própria condição com a do outro, sendo inegável a influência de parâmetros pessoais e sociais neste julgamento. ${ }^{8-9}$

A "saúde percebida" é concebida como a avaliação subjetiva que cada pessoa faz a respeito da qualidade de sua saúde física e mental, podendo incluir uma avaliação atual ou pregressa comparativamente de sua capacidade funcional ou incluir julgamentos de valor sobre a expectativa que se tem sobre sua condição de saúde. ${ }^{8-9}$ Ela representa uma integração individual de muitos aspectos do conceito de saúde, tais como a capacidade de realizar determinadas tarefas, o statusfuncional e 0 status de saúde. ${ }^{10}$

As formas mais divulgadas para apreensão da "saúde percebida" são relatos de: doenças; consumo de medicamentos, de dor e de desconfor tos; alterações percebidas na cognição e autoeficácia, quer seja no âmbito físico ou cognitivo. ${ }^{8}$ Cabe destacar que, mesmo entre pessoas com a mesma idade, existem variações significativas na percepção do estado de saúde, da participação e de autonomia. Tal fato reafirma como o "processo de envelhecimento" é vivenciado de forma peculiar, como ele não se restringe a uma faixa etária e como é consequência de um estilo e de uma concepção adotada ao longo do ciclo vital. ${ }^{11}$

Crença, na presente pesquisa, é compreendida como o suporte cognitivo-social e/ou emocional para convicção de uma pessoa diante de um fato, acontecimento real ou probabilístico, explicando a base em que se fundamenta uma pessoa para adotar uma atitude, comportamento ou pensamento. Segundo Rokeach um sistema de crenças possui cinco categorias, a saber: 1) primitivas de consenso unânime ou do tipo "A"; 2) primitivas de consenso zero ou do tipo "B"; 3 ) de autoridade ou do tipo "C"; 4) derivadas ou do tipo "D" e 5) inconsequentes ou do tipo "E". ${ }^{12}$ Uma pessoa pode possuir várias crenças sobre um mesmo fato, sendo estas estruturadas em cinco categorias que estão, imaginariamente, localizados em um eixo de maneira harmônico a ponto de conferir estabilidade ao sistema de crenças. É possível haver intercâmbio entre elas, possibilitando a análise do sistema de crenças quanto à sua posição no eixo imaginário (centralidade ou perifericidade). ${ }^{12} \mathrm{~A}$ localização da crença no eixo de centralidade/perifericidade possibilita inferir o quanto as crenças são fixas ou passíveis de serem modificadas e pode ser comparado a um átomo, no qual os prótons são as crenças centrais e os elétrons, as periféricas.

As crenças do tipo "A" "são as mais centrais dentro do sistema de crenças, apreendidas pelo encontro direto com o objeto de crença e reforçadas pelo consenso unânime entre pessoas e grupos. Elas representam as "verdades básicas" de uma pessoa sobre a realidade física, social e a natureza do eu". ${ }^{12}$ As crenças do tipo "B" também "são aprendidas pelo contato direto com o objeto de crença, porém têm como referência o próprio eu, envolvendo diretamente a existência e a autoidentidade. Não dependem 
do consenso de pessoas ou grupos para a sua manutenção". ${ }^{12}$ As crenças do tipo "C" dizem respeito à autoridade que é conferida ou atribuída às pessoas. "Elas surgem e são ampliadas a partir de experiências com grupos sociais". ${ }^{12}$ As crenças do tipo "D" constituem um tipo específico de crença de autoridade, na qual a autoridade é originada da influência dos meios de comunicação, de pessoas, de objetos ou de instituições. ${ }^{12}$ As crenças do tipo "E" consistem em situações de preferência, não tendo uma justificativa plausível para sua ocorrência. Elas "estão relacionadas às questões de gosto" e são "consideradas inconsequentes por ter pouca ou nenhuma implicação sobre outras crenças". ${ }^{12}$

Para uma melhor compreensão do sistema de crenças, é importante ressaltar os seguintes pressupostos: 1) atitude é formada pela organização de crenças inter-relacionadas; 2) qualquer crença representa uma predisposição para responder de um modo preferencial ao objeto (foco de sua atenção) e pode possuir tanto um componente afetivo, cognitivo ou comportamental; 3) o afeto ou cognição positiva ou negativa podem ser dirigidos ao objeto daquela atitude ou a outros objetos envolvidos (ou situações paralelas). Exemplo são as motivações que fazem com que um comportamento de solidariedade ou desprezo seja manifestado a respeito de uma pessoa, embora haja concordância ou discordância deste comportamento do ponto de vista, do modo de viver ou de agir de outra pessoa ou grupo; 4) as possibilidades de resposta diante dos objetos, das "situações paralelas" ou comportamentos estão positivamente interligados, uma vez que são motivados pela mesma atitude; 5) um comportamento é o resultado da interação entre atitude (aspectos psicológicos- o que eu penso) e a definição da situação (aspectos objetivos- 0 que eu faço). ${ }^{12}$ Quando uma atitude possui conteúdo equivalente a uma situação, o comportamento é a função da interação entre duas atitudes e da relação com um objeto e com outra situação. ${ }^{12}$

0 fato de uma atitude ser formada pela organização de crenças inter-relacionadas, justifica por que ela descreve, avalia e defende uma ação que possui três componentes, ou seja, o componente cognitivo, afetivo e comportamental. Quando uma crença é ativada por algum fator (quer ele seja uma situação ou um objeto) ela desencadeia uma resposta (cognitiva, afetiva ou comportamental) em relação ao fator, ou seja, em relação ao objeto, à situação de atitude ou à manutenção desta atitude em si mesma. Partindo do pressuposto de que o objeto da atitude insere-se numa situação sobre a qual recai uma atitude, conclui-se que, para ocorrer o comportamento social é necessário ativar, pelo menos, duas atitudes que interajam entre si, sendo que uma delas deve referir-se ao objeto e a outra, à situação. Este fato permite que novas crenças sejam garimpadas a partir da reunião de atitudes.

\section{RESULTADOS E DISCUSSÕES}

Os 20 participantes ficaram assim caracterizados: $55 \%$ tinham 60 e 70 anos de idade (variabilidade dos 62 aos 89 anos de idade); $65 \%$ eram mulheres; $90 \%$ tinham menos do que cinco anos de escolaridade; $85 \%$ faziam tratamento clínico (cardiológico, gastroenterológico ou ortopédico); $75 \%$ consumiam de um a três tipos de medicamentos distintos periodicamente (75\% deles anti-hipertensivos e $30 \%$ ansiolítico/sedativo); $60 \%$ moravam sozinho(a)s ou com o(a) companheiro(a) e $40 \%$ moravam com parentes, sendo que em $90 \%$ a casa era própria e $50 \%$ possuíam ou desenvolviam atividades fora de casa (atividades laborais em $40 \%$ dos casos e atividades no clube ou na igreja em $70 \%$ ) com companhias em $60 \%$ dos casos; $80 \%$ tinham a aposentadoria como única renda; $15 \%$ não aderiam a nenhuma atividade de lazer; $70 \%$ não prestavam, nem recebiam ajuda financeira de ninguém.

0 predomínio de mulheres é pertinente para a relação de idosos por gênero no Brasil;; ${ }^{15}$ a adesão para atividades de lazer é maior entre pessoas que têm companhia, e o fato de metade dos participantes desenvolverem atividades fora do lar demonstra autonomia das pessoas entrevistadas.

A análise de algumas atividades da vida diária (relacionadas ao autocuidado) e instrumentais da vida diária (relacionadas à participação do idoso em seu ambiente social) permite identificar três padrões de caracterização dos participantes para o critério grau funcional, a saber: 1) grau funcional de independência em 17 (75\%), 16 (80\%), 14 (70\%) para realização de atividades do lar; compras e pagamentos e limpeza do lar, respectivamente; 2) grau de independência por unanimidade para atividades de higiene e de alimentação e 3) nível de dependência II, ou seja, necessidade de educação ou orientação para atividades de limpeza do lar entre seis $(30 \%)$ participantes; para atividades de compras e pagamentos entre quatro $(20 \%)$ participantes e para atividades do lar entre três (15\%) participantes. Estes padrões são importantes para determinar se o idoso é capaz ou não de manter uma vida independente.

\section{0 sistema de crenças de Rokeach e o eixo de centralidade/perifericidade}

0 referencial de Rokeach permitiu identificar um sistema composto por 385 crenças classificadas dos tipos A, B, C, D e E, sendo $76,3 \%$ delas tendendo à centralidade e 23,7\% tendendo à perifericidade, ou seja, a maioria das crenças localiza-se próxima ao núcleo do eixo imaginário descrito e denominado por Rokeach de "Eixo de Centralidade/Perifericidade" (Tabela 1). 
Ser Idoso e processo envelhecimento:saúde percebida

Tabela 1: Distribuição das crenças diretas e obtida por inferências pela reunião de duas atitudes/comportamentos, segundo 0 referencial de Rokeach, extraídas dos discursos dos 20 participantes sobre ser ou não idoso ou envelhecido. Juiz de Fora, 2009.

\begin{tabular}{|c|c|c|c|c|c|c|c|}
\hline \multicolumn{2}{|r|}{ Tipos de crenças } & \multicolumn{2}{|c|}{ Crenças diretas } & \multicolumn{2}{|c|}{ Crenças de inferêndias } & \multicolumn{2}{|c|}{ Crenças totais } \\
\hline & & $\mathrm{n}$ & $\%$ & $\mathrm{n}$ & $\%$ & $\mathrm{n}$ & $\%$ \\
\hline \multirow{5}{*}{ 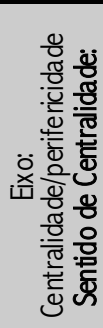 } & Primitiva consenso $100 \%-\mathrm{A}$ & 80 & 31,2 & 72 & 55,8 & 152 & 39,5 \\
\hline & Primitiva consenso zero- $B$ & 84 & 32,8 & 26 & 20,2 & 110 & 28,5 \\
\hline & Autoridade- C & 17 & 6,6 & 15 & 11,6 & 32 & 8,3 \\
\hline & Derivada- D & 28 & 10,9 & 16 & 12,4 & 44 & 11,4 \\
\hline & Inconsequente $-\mathrm{E}$ & 47 & 18,5 & - & - & 47 & 12,3 \\
\hline & TOTAL & 256 & 100 & 129 & 100 & 385 & 100 \\
\hline
\end{tabular}

A análise dos resultados da presente investigação à luz da analogia do sistema de crenças com um átomo permite inferir que a maioria das crenças é difícil de ser modificada por processos educacionais, uma vez que as crenças se encontram próximas em relação ao núcleo e, por isso, fixa dentro do sistema de crenças (Tabela 1 e Quadro 1).

Quadro 1: Crenças extraídas dos discursos dos 20 participantes segundo o tipo de crença do referencial de Rokeach. Juiz de Fora, 2009.

\begin{tabular}{|c|c|}
\hline Crença & $\begin{array}{l}\text { Fragmentos exemplifica dores extraídos dos discursos dos entrevistados } \\
\qquad \text { categoriza dos como crença }\end{array}$ \\
\hline A & $\begin{array}{l}\text { "Eu tomo muita água, como bastante verdura e como banana todo dia } \\
\text { porque faz bem para a saúde". 01; "Antigamente eu näo tinha tempo de } \\
\text { ficar conversando com meus filhos, mas agora, com meus netos e bisneto eu } \\
\text { tenho." } 06\end{array}$ \\
\hline B & $\begin{array}{l}\text { "Eu näo vou à piscina porque tenho medo." 14; "Eu acho muito bom } \\
\text { aposentar mais cedo. Eles poderiam aposentar a gente com } 40 \text { anos." } 18\end{array}$ \\
\hline $\bar{C}$ & $\begin{array}{l}\text { "Não me sinto idosa, graças a Deus." 15; "Bu fico com vergonha quando } \\
\text { te m uma fila grande e eles me passam na frente, mas éa lei". } 13\end{array}$ \\
\hline $\bar{D}$ & $\begin{array}{l}\text { "Eu acho uma vantagem os beneficios direcionados aos idosos. Eles têm que } \\
\text { ter privilégio porque já são velhos". 4; "A minha vida piorou, houve muitos } \\
\text { problemas de famúlia. E foi tudo se acabando. Agora só tenho dois irmäos e } \\
\text { antes eram sete." } 02 \text {; "Eu fiquei } 32 \text { anos sem sair de casa, sem passear } \\
\text { porque comecei a criar meus filhos. E foram } 10 \text { filhos, um atrás do outro". } 7\end{array}$ \\
\hline E & $\begin{array}{l}\text { "Eu faço caminhada porque eu gosto." 9; "Hoje eu gosto de viajar para } \\
\text { Aparecida do Norte." } 12\end{array}$ \\
\hline
\end{tabular}


A genética e a biologia individual são fatores que podem explicar a relevância das atitudes ou comportamentos mencionando limitações ou mudanças advindas do processo de envelhecimento e que subsidiaram o conteúdo das crenças do tipo A. 0 envelhecimento, dentro desta perspectiva, pode ser definido como uma deterioração funcional progressiva e generalizada que resulta na perda da capacidade adaptativa às situações de estresse e no risco para desenvolver doenças relacionadas à velhice. ${ }^{1}$

0 conteúdo das crenças do tipo B foi estruturado em percepções da modificação demográfica que é acompanhada por mudanças nas estruturas e nos papéis da família, assim como nos padrões de trabalho. ${ }^{16} \mathrm{~A}$ urbanização, a migração de jovens para cidades à procura de trabalho, o surgimento de famílias menores e a inserção feminina na força de trabalho formal significam que menos pessoas estão disponíveis para desenvolverem atividades de cuidado das pessoas idosas, fazendo com que elas percam "espaço na sociedade". ' Outro fator é a diminuição ou o empobrecimento das relações familiares, laborais ou sociais, fato evidenciado pelos fragmentos dos discursos dos idosos entrevistados.

Cabe acrescentar que fatores de transição como o caso da aposentadoria favorecem para o empobrecimento do nível de convivência dos idosos, geram perda de renda e vácuo relacional na convivência do quotidiano, uma vez que reduzem a diversidade de oportunidades para o convívio social. Assim, a aposentadoria favorece a perda dos vínculos laborais, e as limitações advindas da idade e do envelhecimento faz com que os idosos tenham suas atividades restritas.

A recomendação médica adotada pelos idosos, tendo como justificativa a promoção da saúde e a prevenção de danos e doenças, foram conteúdos abordados pelas crenças do tipo C 17. Sabe-se que a participação em atividades físicas pode retardar os declínios funcionais e as limitações deles provenientes, além de promover o contato social e de diminuir o aparecimento de doenças crônicas em idosos saudáveis ou doentes crônicos a ponto das pessoas idosas ficarem independentes o máximo possível, pelo período de tempo mais longo. ${ }^{1}$

0 Estatuto do idoso e seus desdobramentos políticos e sociais constituem um paradigma em termos de política pública traduzindo em apoio e favorecimento da inserção do idoso no contexto social ${ }^{18}$ conforme consta dos conteúdos das crenças do tipo D. Os "benefícios" explicitados no seu conteúdo não correspondem a ações paternalistas isoladas, mas traduzem estratégias de vinculação do idoso ao seu núcleo familiar e estímulo à participação social. No art. $3^{\circ}$ está explicitada a "obrigação da família, da comunidade, da sociedade e do Poder Público de assegurar ao idoso, com absoluta prioridade, a efetivação do direito à vida, à saúde, à alimentação, à educação, à cultura, ao esporte, ao lazer, ao trabalho, à cidadania, à liberdade, à dignidade, ao respeito e à convivência familiar e comunitária". ${ }^{18}$ As crenças do tipo $\mathrm{E}$, ou seja, inconsequentes, exprimem preferências pessoais e questões de gosto.

Saúde percebida- A saúde percebida dos participantes para o número de atividades desenvolvidas ficou assim caracterizada: $70 \%$ delas diminuíram, $25 \%$ se mantiveram e $5 \%$ aumentaram. Foi identificado que a maioria dos idosos se considera mais conservado e animado atualmente para se inserirem em atividades diversas quando comparados a momentos pregressos, fato que os fazem se autoavaliarem positivamente (Tabela 2).

Tabela 2: Saúde percebida de ser/estar ou não idoso ou envelhecido, Juiz de Fora 2009.

\begin{tabular}{lcclccc}
\hline Autoconceito sobre sua conservação & N & $\%$ & Autoconceito sobre sua disposição & n & \% \\
\hline Muito mais novo(a) & 2 & 10 & Muito mais animado(a) & 3 & 15 \\
Conservado(a) & 11 & 55 & Animado(a) & 12 & 60 \\
Adequado(a) & 5 & 25 & Adequado(a) & 5 & 25 \\
Desgastado(a) & 1 & 5 & Desanimado(a) & - & - \\
Velho(a) & 1 & 5 & Muito(a) desanimado(a) & - & - \\
\hline Total & 20 & 100 & Total & 20 & 100 \\
\hline
\end{tabular}

As atividades laborais foram mencionadas entre aquelas que se extinguiram com a idade e "ficar à toa", "bordar" e "fazer atividade física" mencionadas entre as novas atividades que foram inseridas com a idade.

A concepção de ser idoso ou envelhecido, segundo a saúde percebida dos participantes, demonstrou que $55 \%$ e $60 \%$ deles não se sentem idosos e nem envelhecidos respectivamente (Quadro 2). Eles adotam o paradigma da própria idade para julgar uma pessoa idosa somente quando ela possui idade superior à sua. Há similaridade de concepção de ser idoso/envelhecido, ao se comparar os dados obtidos com a proposta do envelhecimento ativo, ${ }^{1}$ a partir da identificação dos seguintes determinantes: 1) sociais - não fazer nada, ser dependente e estar mais disposto para inserir-se socialmente; 2) comportamentais - estar alegre, sentir-se cansado ou desanimado, não ter vaidade e aparentar velhice e 3) pessoais - ter peso e memória alterados, ficar doente, ter idade compatível com ser idoso. 
Ser Idoso e processo envelhecimento:saúde percebida

Quadro 2: Distribuição das concepções dos 20 participantes para ser "envelhecido" e "idoso". Rio Novo, mai/jul 2008.

\begin{tabular}{|c|c|c|c|}
\hline $\begin{array}{l}\text { Categorias } \\
\text { emergentes }\end{array}$ & $(*)$ Ser idoso & $\begin{array}{c}\text { (*)Estar } \\
\text { envelhecido }\end{array}$ & $\begin{array}{l}\text { Fragmento que exemplifica a concepção de ser uma pessoa idosa ou envelhecida extraido do discurso dos } \\
\qquad \text { entrevistados }\end{array}$ \\
\hline Alegrar-se & $8: 13$ & & "Uma pessoa idosa é velha, mas é uma pessoa que sai, que ri, que brinca". \\
\hline Cansar-se & 9 & 20 & "Uma pessoa idosa já trab ahou muito e ainda luta como eu". "A pessoa envelhecida é cansada". \\
\hline Depender & $1 ; 2 ; 6 ; 11$ & $7 ; 13$ & "A pessoa idosa toma banho sozinha...". "A envelhecida precisa que os outros façam para ela". \\
\hline Desarimar-se & 15 & & "Eu acho que a pessoa idosa é aquela que se deixa levar pelo desânimo". \\
\hline Aparentar & $1 ; 16 ; 8$ & & "Idoso é a pessoa que às vezes é nova, mas tem aparência de velho. É a aparência". \\
\hline Adoecer & & $2 ; 9 ; 15 ; 16 ; 17$ & "Eu acho que envelhecida é quando a pessoa está doente." \\
\hline Não fazer nada & 27;10;11;12; & $2 ; 5 ; 8 ; 9 ; 10 ; 12 ;$ & "A pessoa idosa não aguenta fazer um serviço". "A pessoa envelhecida só quer ficar em casa sem fazer nada." \\
\hline Não ter vaidade & & 2 & "Envelhecidas são essas pessoas que não têm vaidade nenhuma" \\
\hline Desmemoriar-se & & $11: 14$ & "Envelhecida é a pessoa que perde a memória" \\
\hline Idade & $4 ; 10 ; 19$ & $4 ; 10$ & "Passou de 80, já é idoso." "Pessoa envelhecida é uma pessoa que já tem uma idade avançada" \\
\hline Participar & 5 & & "Idoso é aquele que participa das coisa, que passeia..." \\
\hline Perder peso & & 1 & "Envelhecida é aquela pessoa que está mais magrinha." \\
\hline
\end{tabular}

\section{CONSIDERAÇÕES FINAIS}

A composição da amostra e a diversidade de informações obtidas permitiram identificar entre os 20 idosos entrevistados que o conceito de envelhecimento e de ser idoso está vinculado ao estado emocional, ao nível de dependência, à perda de memória, autonomia, peso e participação social, à alteração da aparência e do estado de saúde, dentre outros. Estas concepções auxiliaram na identificação de comportamento, ações e atitudes, definidos por uma estratégia adicional capaz de captar novas crenças, dentro do Sistema de Crenças de Rokeach. 0 sistema de crenças foi composto por 385 crenças dos tipos A, B, C, D e $E$, sendo $76,3 \%$ delas tendendo à centralidade, ou seja, a maioria das crenças é difícil de ser modificada por processos educacionais, uma vez que se encontram nuclearmente dentro do sistema de crenças. Na autoavaliação dos idosos para sua saúde percebida, $70 \%$ deles diminuíram suas atividades; a maioria se considera mais conservado e animado atualmente e não se sente idoso nem envelhecido. Os participantes se acham joviais e adotam o paradigma da própria idade para julgar uma pessoa idosa somente quando possuem idade superior a sua. Houve predomínio de duas concepções de envelhecimento (viver uma nova vida e viver com a deterioração dos sistemas corporais, da autonomia e das relações interpessoais).

Os resultados da presente pesquisa, do ponto de vista da atuação laboral dos Enfermeiros e dos Educadores Físicos, permitiram identificar a presença de dicotomia existente entre as políticas de saúde (Estatuto do Idoso e Envelhecimento Ativo) e a realidade da população idosa investigada. A identificação da concepção de saúde percebida e do sistema de crenças de Rokeach sugere a necessidade de: 1) aprofundar a temática do processo de envelhecimento entre os profissionais de saúde em uma abordagem multiprofissional para a área de saúde e áreas afins e 2) delinear novas investigações usando metodologia que permita a compreensão de crenças, atitudes e comportamentos com a finalidade de subsidiar a construção de alicerces teóricos operacionais.

\section{REFERÊNCIAS}

1.World Health Organization- WHO. Noncomunicable Diseases and Mental Health Promotion Department. Ageing and life course. Active ageing. A Policy Framework. Geneva: 2002.

2. Organização Pan-Americana da Saúde- OPS. Envelhecimento ativo: uma política de saúde. Brasília (DF): Ministério da Saúde; 2005: 13.

3. Lei $n^{0}$. 8.842 de 4 de janeiro de 1994. Dispõe sobre a Política Nacional do Idoso, cria o Conselho Nacional do Idoso e da outras providências. Brasília (DF): Brasília: Ministério da Saúde; 1994.

4. Pereira RJ, Cotta RMM, Priore SE. Políticas sobre envelhecimento e saúde no mundo. Mundo Saúde. 2005 out/dez; 29(4): 475-83.

5. Decreto $n^{0} 1.948$, de 3 de julho de 1996. Regulamenta a Lei nº. 8.842, que dispõe sobre a Política Nacional do Idoso. Brasília(DF); 1996.

6. Marin MJS, Cecílio LCO, Rodrigues LCR, Ricci FA, Druzian S. Diagnósticos de enfermagem de idosas carentes de um programa de saúde da família (PSF). Esc Anna Nery. 2008 [ periódico on-line] 12(2): 278-84.

7. Lindolpho MC, Sá SPC, Leite AP, Maciel CO, Silva INT. Atendimento domiciliário ao idoso dependente de cuidados de enfermagem- realidade e dificuldades. Rev Enferm Atual. 2007 maio/jun; 39(7): 25-32. 
8. Neri AL. Bem-estar físico e saúde percebida: Um estudo comparativo entre homens e mulheres adultos e idosos, sedentários e ativos. [tese]. Campinas (SP): Faculdade de Educação, Universidade Estadual de Camoinas; 2001.

9. Devitta A, Neri AL, Padovani CR. Saúde percebida em homens e mulheres sedentários e ativos, adultos jovens e idosos. Salusvita. 2006; 25(1):2334.

10. Teixeira INDO, Neri AL. Envelhecimento bem-sucedido: uma meta no curso da vida. Psicol USP. mar 2008; 19(1):81-94.

11. Colina A, Depp PHD, Dilip V, Jeste MD. Definitions and predictors of successful aging: a comprehensive review of larger quantitative studies. Am J Geriatr Psychiatr. 2006 Jan; 14: 6-20.

12. Rokeach M. Crenças, atitudes e valores: uma teoria de organização e mudança. Rio de Janeiro: Interciência; 1981.

13. Lakatos EM, Marconi MA. Fundamentos de metodologia científica $7^{\text {a }}$ ed. São Paulo: Atlas; 2010.

14. Bardin L. Análise de conteúdo. Lisboa: Ed 70; 2009.

15. Pinto PF, Fernandes AA, Botelho MA. Envelhecimento activo e estilos de vida saudáveis: a actividade física. Forum Sociológico. Envelhecimento activo: um novo paradigma 2007; Série II (17): 43-52.

16. Nasri F. 0 envelhecimento populacional no Brasil: demografia e epidemiologia do envelhecimento. Einstein. 2008; 6(supl 1): S4-S6.

17. Monteiro LZ, Fiani CRV, Freitas MCF, Zanetti ML, Foss MC. Redução da pressão arterial, da IMC e da glicose após treinamento aeróbico em idosas com diabete tipo 2. [periodico on-line]. Arq Bras Cardiol. 2010 out; 95(5): 563-70.

18. Lei n 10741, de 01de outubro de 2003. Dispôe sobre o Estatuto do Idoso e dá outras providências. $2^{a}$ ed. Brasilia (DF); 2008. (Série E: Legislação d 